\title{
HARTMANN, Peter Claus, Kulturgeschichte des \\ Heiligen Römischen Reiches 1648 bis 1806, Verfassung, Religion und Kultur
}

\section{Christophe Duhamelle}

\section{OpenEdition}

1 Journals

\section{Édition électronique}

URL : http://journals.openedition.org/ifha/1190

DOI : $10.4000 /$ ifha. 1190

ISSN : 2198-8943

\section{Éditeur}

IFRA - Institut franco-allemand (sciences historiques et sociales)

\section{Référence électronique}

Christophe Duhamelle, " HARTMANN, Peter Claus, Kulturgeschichte des Heiligen Römischen Reiches 1648 bis 1806, Verfassung, Religion und Kultur », Revue de l'IFHA [En ligne], Date de recension, mis en ligne le 01 janvier 2002, consulté le 22 septembre 2020. URL : http://journals.openedition.org/ifha/ 1190 ; DOI : https://doi.org/10.4000/ifha.1190

Ce document a été généré automatiquement le 22 septembre 2020.

(CIFHA 


\title{
HARTMANN, Peter Claus, Kulturgeschichte des Heiligen Römischen Reiches 1648 bis 1806, Verfassung, Religion und Kultur
}

\author{
Christophe Duhamelle
}

1 Vaste ambition que d'écrire une histoire « culturelle » de l'Allemagne moderne, alors même que l'historiographie récente fait parfois, à un mot près, la même constatation que le curé de campagne de Bernanos : tout est culture. Disons le d'emblée : ce n'est pas au plan de la réflexion théorique et du renouvellement conceptuel que se situent les atouts les plus évidents du livre de P.C.H., qui reste attaché à une conception assez restreinte de la « culture » (les institutions, les cours, les Églises et les arts constituent l'essentiel de ces cinq cents pages). Il suffira peut-être de dire que la bibliographie ignore des noms comme Hans Erich Bödeker ou Rudolf Schenda pour marquer les limites d'un volume dont l'écriture claire et agréable n'évite pas ici ou là quelques simplicités. Pourtant, le présent ouvrage mérite tout à fait de prendre sa place aux côtés d'autres synthèses sur le même thème (on pense bien sûr par exemple aux trois tomes de Richard van Dülmen, Kultur und Alltag in der Frühen Neuzeit, München, 1990-1994), car il se distingue par trois aspects.

2 Il s'agit d'abord d'une histoire culturelle du Saint-Empire. Dans la lignée d'un renouvellement historiographique dont le Bulletin a souvent rendu compte, ce sont ici toutes les spécificités des institutions impériales qui sont présentées sous un angle culturel. La diversité des territoires et des statuts constituait en effet un vivier favorable aux créations les plus variées et multipliait, dans les domaines artistique et intellectuel, les pôles concurrents et féconds. Sous cet angle, P.C.H. restitue le fractionnement des territoires et des cours sans y substituer l'unité d'une abstraction factice, et rappelle les grands traits d'une vie institutionnelle favorisant l'affirmation du quant-à-soi, les pratiques distinctives mais aussi les contrepoids, les circulations et les modèles communs (on regrette cependant que des travaux comme ceux d'Helmut 
Gabel ne soient pas plus sollicités). Second thème principal de l'ouvrage, les différences religieuses, et leur constitution en cultures confessionnelles, sont présentées de manière efficace en partant des positions théologiques (images, liturgie, musique...) pour détailler ensuite leur traduction dans l'architecture, les arts, mais aussi les modes de piété populaire (de manière parfois un peu mécaniste toutefois). Le troisième point fort, enfin, réside dans la masse des informations fournies, appuyées sur une abondante iconographie : l'ouvrage, en ce sens, est une excellente introduction à la diversité des formes d'expression religieuse et artistique dans le Saint-Empire moderne. Soucieux d'équilibrer les différentes régions d'Allemagne, P.C.H. présente donc une synthèse dont l'ambition, plus typologique que conceptuelle, n'est pas sans mérites. Il y a là une somme de connaissances que, sur de nombreux points, on ne trouve nulle part rassemblées de manière aussi commode. C'est surtout, en définitive, le pluralisme de la vie culturelle de l'Empire moderne (ce pluralisme dont d'autres ouvrages donnent le sentiment qu'il offusque, tout en l'exacerbant, leur désir d'abstraction) qui constitue le sujet de ce livre.

Christophe DUHAMELLE 